\section{Anaesthetic manage- ment of infants requiring endobronchial argon laser surgery}

Ann G. Bailey MD, Robert D. Valley MD, Richard G. Azizkhan MD, Robert E. Wood PhD MD

\begin{abstract}
Small infants with endobronchial lesions primarily due to traumatic suction catheter injuries are now undergoing argon laser surgery to remove obstructive tissue. Providing an anaesthetic for these infants can be challenging because of the small airways involved which must be shared by the anaesthetist and the surgeon. We have performed 30 argon laser endobronchial surgeries in nine infants. The lungs of the majority of patients were ventilated through a tracheostomy intraoperatively, while the surgeon passed the argon laser fibre through the suction port of a fibreoptic bronchoscope which was passed transnasally. Three infants were too small to allow passage of the fibreoptic bronchoscope past an artificial airway. In these patients surgery and ventilation were accomplished through a rigid bronchoscope. Three larger patients without tracheostomies were managed with a modified nasal airway for intraoperative ventilation in conjunction with the fibreoptic bronchoscope.
\end{abstract}

Les lésions endobronchiques chez le nourrisson sont dues principalement à des traumatismes causés par des cathéters de succion trachéale. La chirurgie avec laser à l'argon permet l'exérèse de ces lésions lorsqu'elles causent de l'abstruction. $L$ 'anesthésie pour ce type d'intervention représente un défi dû à la difficulté d'accès aux petites voies aériennes devenues à la fois le champ de travail de l'anesthésiste et du chirurgien. Nous avons réalisé 30 chirurgies au laser à l'argon pour exérèse de lésions endobronchiques chez neuf nourrissons. La majorité des patients avaient une trachéostomie permettant la ventilation

\section{Key words}

ANAESTHESIA: paediatric;

ANAESTHETIC TECHNIQUES: endobronchial;

EQUIPMENT: lasers;

SURGERY: lasers.

From the Departments of Anesthesiology, Surgery, and Pediatrics, University of North Carolina School of Medicine, Chapel Hill, North Carolina.

Address correspondence to: Dr. Ann Bailey, Department of Anesthesiology University of North Carolina School of Medicine, CB \#7010, Chapel Hill, North Carolina 27514.

Accepted for publication 28th February, 1992 pulmonaire pendant la chirurgie. La fibre du laser à l'argon était passée par l'orifice de succion d'un bronchoscope flexible à fibres optiques introduit par le nez. Chez trois patients trop petits, il fut impossible d'introduire le bronchoscope flexible en présence du tube de trachéostomie. La chirurgie et la ventilation ont alors été faites à l'aide d'un bronchoscope rigide. Chez trois patients plus grands sans trachéostomie, la ventilation et l'introduction du bronchoscope flexible furent réalisées à l'aide d'une canule nasale modifiée.

Acquired bronchial stenosis resulting from repeated endobronchial injury usually related to suction catheter trauma is a potential cause of morbidity and mortality in small infants who require prolonged tracheal intubation and respiratory support. Ventilation of portions of the lung may be compromised by bronchi which have scarring and granulation tissue occluding much of the lumen. Increasing oxygen requirements or ventilator support may herald the need to remove the obstructing tissue. A new and effective endoscopic laser procedure to treat these patients has been used in our institution. The management of small children undergoing endoscopic laser procedures can be extremely challenging and presents special concerns for the anaesthetist. The problems and special considerations of airway laser therapy are compounded by the size limitations of the infantile airway, which must be shared between the surgeon and anaesthetist. Depending on the size and weight of the infant and whether a tracheostomy was present, we have used three different intraoperative techniques for managing the airway. While the surgical management and outcome have been previously reported, ${ }^{1}$ we wish to describe our anaesthetic and airway experience in the first 30 endobronchial laser procedures in nine infants (Table).

\section{Techniques}

Technique 1 (Figure 1)

Children weighing more than $3 \mathrm{~kg}$ who had tracheostomies because of prolonged ventilatory support or subglottic stenosis were managed with the following technique. The 
TABLE Patient characteristics grouped by technique

\begin{tabular}{llllll}
\hline Technique & $\begin{array}{l}\text { Number of } \\
\text { patients }\end{array}$ & $\begin{array}{l}\text { Average age in } \\
\text { months (range) }\end{array}$ & $\begin{array}{l}\text { Average weight } \\
\text { in } \mathrm{kg} \text { (range) }\end{array}$ & $\begin{array}{l}\text { Principle diagnoses } \\
(\mathrm{n})\end{array}$ & $\begin{array}{l}\text { Number of } \\
\text { treatments }\end{array}$ \\
\hline 1 & 5 & $21(6-39)$ & $9.6(3.8-18)$ & $\begin{array}{l}\text { Prematurity/BPD* (4) } \\
\text { Laryngotracheal cleft (1) }\end{array}$ & 21 \\
2 & 3 & $1.4(0.8-2)$ & $2.0(1.3-2.8)$ & $\begin{array}{l}\text { Prematurity /BPD* (2) } \\
\text { Cervical teratoma (1) }\end{array}$ & 3 \\
3 & 3 & $16(4-36)$ & $7.0(4.1-13)$ & Prematurity/BPD* (3) & 6 \\
\hline
\end{tabular}

*Bronchopulmonary dysplasia (BPD).

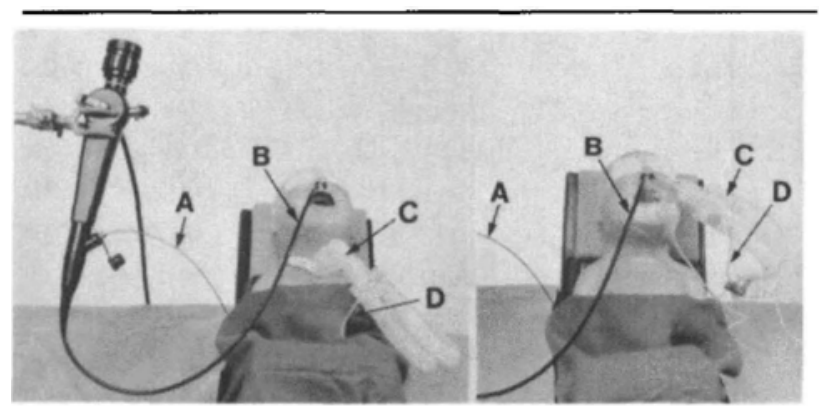

FIGURE 1 Model depicting technique 1 (left); and technique 3 (right) ( $\mathrm{A}=$ argon laser fibre, $\mathrm{B}=$ fibreoptic bronchoscope, $\mathrm{C}=$ anaesthetic circuit, $\mathrm{D}=\mathrm{CO}_{2}$ sampling line).

patients were taken to the operating room where a threelead ECG, pulse oximetry, and a non-invasive blood pressure monitor were applied. Anaesthesia was induced via the tracheostomy with $\mathrm{N}_{2} \mathrm{O}, \mathrm{O}_{2}$, and isoflurane. Capnography and gas analysis were utilized. Intravenous access was established and atropine $0.01 \mathrm{mg}^{-1}$ administered. Neuromuscular blockade was achieved with vecuronium, and gas exchange was controlled with conventional mechanical ventilation. A $3.5 \mathrm{~mm}$ flexible bronchoscope (Olympus BF3C10, Olympus Corp, Lake Success, NY) was passed transnasally and then alongside the tracheostomy cannula. The target lesion was visualized, and a 300 micron argon laser fibre (HGM Medical Laser Systems, Salt Lake City, UT) was passed through the bronchoscope suction channel. After discontinuation of $\mathrm{N}_{2} \mathrm{O}$ and reduction of the $\mathrm{O}_{2}$ concentration to $30 \%$, the laser fibre was positioned under direct vision adjacent to or in contact with the obstructing endobronchial tissues. The laser was fired (2.5-3.5 watts in $0.5 \mathrm{sec}$ pulses) parallel to the bronchial wall to minimize the risk of airway perforation. Laser treatments were confined to one main bronchus and segmental bronchi to decrease the potential consequences of mucosal swelling. Following laser treatment, the bronchoscope was removed, isoflurane was discontinued and muscle relaxation was reversed. After return of spontaneous ventilation, patients were taken to the recovery room.

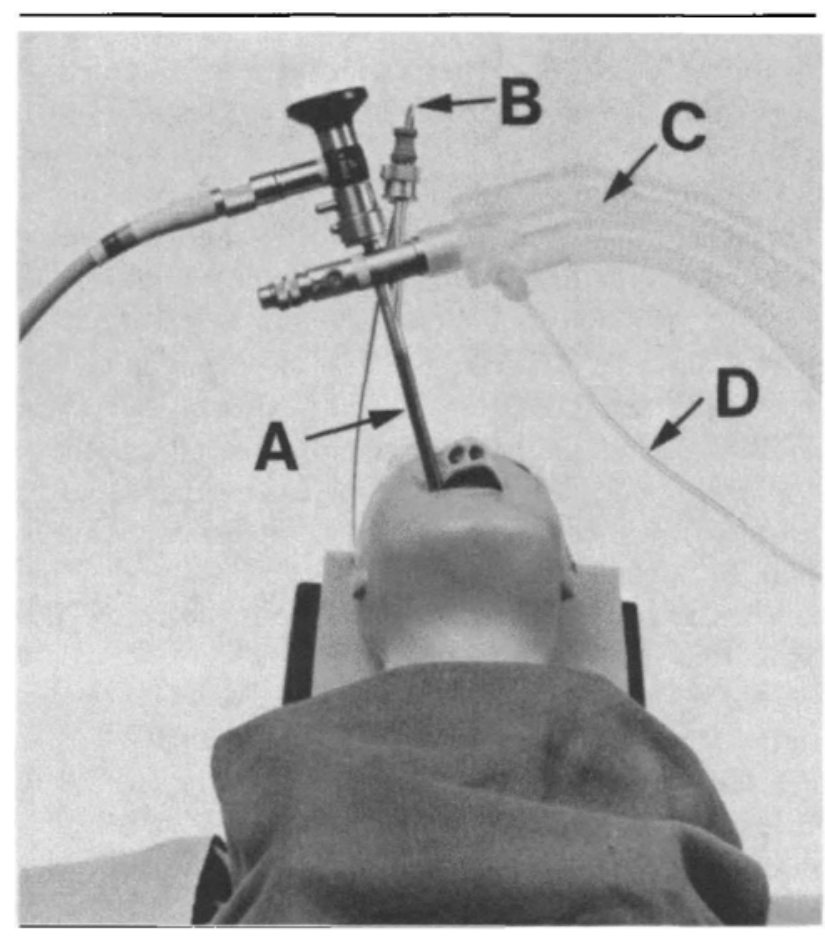

FIGURE 2 Model depicting technique 2. (A = rigid bronchoscope, $\mathrm{B}=$ argon laser fibre, $\mathrm{C}=$ anaesthetic circuit, $\mathrm{D}=\mathrm{CO}_{2}$ sampling line).

\section{Technique 2 (Figure 2)}

Children weighing less than $3 \mathbf{~ k g}$ who required laser therapy were managed similarly regardless of their preexisting airway. On arrival in the operating room, standard monitors were placed as in technique 1. Venous access was assured, and atropine was given. Isoflurane, vecuronium, air and $\mathrm{O}_{2}$ were used for anaesthesia. Controlled ventilation was instituted either via a preexisting artificial airway (i.e., tracheostomy or endotracheal tube) or by mask. After adequate anaesthesia was established, the tracheas of all patients were intubated orally with a 3.0 mm I.D. Storz rigid bronchoscope (Karl Storz Inc, Tuttlingen, FRG). Previously existing endotracheal airways were removed prior to inserting the rigid bronchoscope. Anaesthetic inhalation agents were delivered, and ventilation was 
controlled through a ventilating side-port of the bronchoscope. The laser fibre was placed, positioned and manipulated through the bronchoscope. The laser was employed in a fashion similar to technique 1. Following laser treatment the tracheas were reintubated with either an oral tracheal tube or the preexisting tracheostomy. All patients were returned to the intensive care nursery and resumed their preoperative ventilation status shortly after arrival.

\section{Technique 3 (Figure 1)}

A third method has been used for children weighing more than $3 \mathrm{~kg}$ without a tracheostomy. The children were taken to the operating room, and standard monitors were placed. Mask induction of anaesthesia with halothane, $\mathrm{N}_{2} \mathrm{O}$ and $\mathrm{O}_{2}$ was performed, and intravenous catheters were inserted. Aropine and vecuronium were given intravenously. Ventilation was controlled, and anaesthesia was maintained with isoflurane, air, and $\mathrm{O}_{2}$. A shortened endotracheal tube with a $\mathrm{CO}_{2}$ monitoring lumen (Mallinkrodt, Inc., Glens Falls, New York) was passed via the right nostril into the posterior oropharynx. Ventilation was controlled via this nasal airway. The flexible bronchoscope was passed through the opposite nostril, past the glottis to the level of the endobronchial lesion. During the procedure an orogastric tube was placed to decompress the stomach, and the mouth was sealed with an occlusive dressing (Opsite ${ }^{(x)}$ ) to prevent leakage of anaesthetic gases. The laser fibre was passed through the suction port of the flexible bronchoscope and the airway lesions were treated as in techniques 1 and 2. Following laser treatment, muscle relaxation was reversed and anaesthetic agents were discontinued. All patients were taken in satisfactory condition to the recovery room after the return of spontaneous ventilation.

\section{Results}

Nine patients underwent a total of 30 argon laser treatments for severe endobronchial stenosis (Table). All patients were treated with steroids and antibiotics postoperatively. Two infants who needed multiple laser treatments utilized more than one airway management technique as they grew or had their tracheostomy decannulated. Five children underwent 21 procedures using technique 1 . Three very small infants were treated with technique 2. Technique 3 was utilized six times for three patients. There were no intraoperative anaesthetic or airway complications. Only one postoperative complication occurred. A $1300 \mathrm{~g}$ infant developed a tension pneumothorax following unplanned tracheal extubation 12 $\mathrm{hr}$ after surgery. Vigorous ventilation with high pressures during resuscitation was felt to have been responsible for this complication. The child was successfully managed with reintubation and chest tube placement. Her trachea was extubated one week later without difficulty. Follow-up evaluations with fibreoptic bronchoscopy revealed improvements in all patients. One child subsequently died of apparently unrelated sepsis.

\section{Discussion}

Laser surgery is frequently used in children and adults for ablating airway lesions. The $\mathrm{CO}_{2}$ laser is often used for upper airway lesions such as those involving the larynx or proximal trachea. Because of its nonadaptability to fibreoptic delivery systems, the $\mathrm{CO}_{2}$ laser is not easily used for lesions in the lower airways. The Neodymium-yttrium aluminum garnet (Nd-YAG) laser can he used for distal airway procedures in adults via a fibreoptic system, but the currently available laser wands are too large for use in the small distal airways of infants. The $\mathbf{3 0 0}$ micron laser fibre of the argon laser has proved to be very effective in the small airways of paediatric patients and can be passed through appropriately sized flexible and rigid bronchoscopes.

While there are a number of techniques described for providing anaesthesia to patients requiring laser surgery of the airways, many are applicable only to surgery for lesions of the larynx or proximal trachea. ${ }^{2-5}$ All of the patients in this review presented with lesions distal to the carina which were thought to be the result of suction catheter trauma. Seven of the nine patients had lesions involving a mainstem bronchus, while the other two patients had lesions of the right lower lobe bronchus or the bronchus intermedius. Control of the small shared airway when the surgeon is deep into the bronchus can present logistical problems. Five of the nine patients presented for laser surgery with a preexisting tracheostomy and adequate tracheal diameter. This allowed for easy ventilation via the tracheostomy while the flexible bronchoscope was passed from above alongside the tracheostomy cannula (technique 1). The laser fibre was always distal to the tip of the tracheostomy cannula and did not pose a fire hazard to the cannula itself. Standard anaesthetic precautions for laser surgery were taken, i.e. patient immobility, discontinuation of $\mathrm{N}_{2} \mathrm{O}$, and delivering relatively low concentrations of $\mathrm{O}_{2}$ mixed with air prior to firing the laser. ${ }^{2}$ Some patients with supplemental oxygen requirements preoperatively required inspired oxygen concentrations of greater than $30 \%$ during laser firing. The oxygen concentration was maintained at the lowest concentration to allow adequate oxygenation (measured by pulse oximetry).

During the firing of the laser, ventilation was stopped to assure minimal movement of the surgical field. This necessitated use of muscle relaxants rather than allowing spontaneous ventilation. In several instances, an inspiratory pause was useful in stenting the airway open, allowing better visualization for the laser surgery. A few 
episodes of mild arterial desaturation (between $85 \%$ and 95\%) occurred during ventilation pauses as a result of the lowered $\mathrm{FIO}_{2}$ and preexisting lung disease. These were easily managed by informing the surgeon and resuming ventilation.

The small diameter of the trachea was the primary reason that technique 2 was used in infants under $3 \mathrm{~kg}$. Neither the upper airway diameter nor the internal diameter of the tracheostomy cannula or tracheal tube would allow both for passage of the flexible bronchoscope and maintenance of an adequate airway for ventilation. Unlike the larger patients with preexisting tracheostomies, it was not feasible to place the fibreoptic bronchoscope alongside a tracheostomy cannula. In technique 2 , the rigid bronchoscope allowed ventilation via the sideport as well as a port for the laser fibre. Manipulation of the laser fibre within the rigid bronchoscope is more difficult and restrictive than with the flexible bronchoscope. The flexible bronchoscope allows precise control and easy targeting of the laser fibre and is the preferred method whenever possible.

The three larger patients who came to us without preexisting artificial airways presented the greatest challenge. One of these patients had five previous procedures with a tracheostomy in place which had since been removed. The smallest of the three patients previously had had laser surgery with the rigid bronchoscope when his weight was less than $3 \mathrm{~kg}$ (technique 2). With subsequent growth to $4.5 \mathrm{~kg}$, his airway was now thought to be large enough to allow use of the fibreoptic bronchoscope. The tracheas of all three patients could have been intubated conventionally but the inner diameter of appropriately-sized endotracheal tubes was insufficient to allow both the flexible bronchoscope and adequate ventilation. The patients' tracheas were large enough to allow use of the $3.5 \mathrm{~mm}$ FB but insufficient to allow our smallest endotracheal tube to pass alongside the FB through the glottis. Jet ventilation via a small catheter passed into the trachea was initially considered as a possible ventilation method during the laser surgery but was discounted because of potential complications such as pneumothorax and pneumomediastinum, as well as the possibility of blowing charred material further down the bronchial tree. ${ }^{5}$

The technique we describe is a modification of a method used to control the airway while performing pulmonary lavage in paediatric patients. ${ }^{6} \mathrm{We}$ originally attempted to continue mask ventilation and to allow the surgeons to place their flexible bronchoscope through a port on the elbow adapter of the mask. This proved to be unacceptable, as small movements of the mask would move the bronchoscope at potentially critical moments. Ventilating via a nasal airway allowed the surgeons to have undisturbed access to the other nostril. The nasal airway has been very effective, but can cause gastric distention with positive pressure ventilation. For this reason, it is important to decompress the stomach continually with an orogastric tube if a gastrostomy is not already in place. Although halothane was used for ease of mask induction, isoflurane was used for the anaesthetic maintenance. With preexisting pulmonary disease and the frequent need to stop ventilation during lasering, hypercarbia was a potential problem. Our $\mathrm{CO}_{2}$ monitoring for this technique was not extremely accurate, and the absence of documented high end-tidal $\mathrm{CO}_{2}$ from the oropharynx did not guarantee normocarbia. Both halothane and hypercarbia are known to predispose to arrhythmias in paediatric patients. ${ }^{7}$ Isoflurane was used to decrease the possibility of arrhythmias in the presence of hypercarbia. No arrythmias were seen intraoperatively in any of the patients in this series.

In summary, fibreoptic laser procedures are now performed in the distal airways in infants and children. They present a challenge to the anaesthetist in airway management and anaesthesia delivery. The size of the patient and the presence or absence of a tracheostomy preoperatively will determine the optimal method of airway management. Communication and cooperation with the surgeons and pulmonologists both preoperatively and intraoperatively is essential in order to share the airway effectively and safely.

\section{Acknowledgements}

The authors wish to thank Drs. Fred Spielman and Enid Kafer for their kind review of this manuscript.

\section{References}

1 Azizkhan RG, Lacey $S R$, Wood RE. Acquired symptomatic bronchial stenosis in infants: successful management using an argon laser. J Ped Surg 1990; 25: 19-24.

2 Hermans JM, Bennett MJ, Hirshman CA. Anesthesia for laser surgery. Anesth Analg 1983; 62: 218-29.

3 Johans TG, Reichert TJ. An insufflation device for anesthesia during subglottic carbon dioxide laser microsurgery in children. Anesth Analg 1984; 62: 368-70.

4 Van der Spek AF, Spargo PM, Norton ML. The physics of lasers and implications for their use during airway surgery. Br J Anaesth 1988; 60: 709-29.

5 Keon TP. Anesthetic considerations for laser surgery. Int Anesthesiol Clin 1988; 26: 50-2.

6 McKenzie B, Wood RE, Bailey A. Airway management for unilateral lung lavage in children. Anesthesiology 1989; 70: 550-3.

7 Rolf $N$, Coté $C$. Persistent cardiac arrhythmias in pediatric patients: effects of age, expired carbon dioxide values, depth of anesthesia, and airway management. Anesth Analg 1991; 73: 720-4. 